\title{
Separated-Flow Considerations for Pressure-Atomized Combusting Monopropellant Sprays
}

\author{
T.-W. Lee, ${ }^{*}$ L.-K. Tseng, ${ }^{*}$ and G. M. Faeth $\dagger$ \\ University of Michigan, Ann Arbor, Michigan 48109
}

\begin{abstract}
The drop and spray combustion properties of the hydroxyl-ammonium nitrate (HAN)-based monopropellant LGP 1845 were studied. Drop-burning rates were measured with drops supported in a combustion gas environment at pressures of 0.2-7.0 MPa. Some internal gasification of drops-causing swelling, partial bursting, and microexplosions-was observed throughout this region, but these disturbances decreased with increasing pressure. Effective drop-burning rates (including effects of both surface gasification and bursting) were relatively constant, ca. $10 \mathrm{~mm} / \mathrm{s}$, and were consistent with earlier strand-burning-rate measurements of gelled propellant. Pressure-atomized combusting sprays were studied in combustion gas environments at pressures of 3-9 MPa. The liquid-containing region was significantly larger than earlier measurements of Birk and Reeves, ${ }^{19}$ as well as predictions based on the locally-homogeneous-flow approximation of multiphase flow theory. In conjunction with drop-trajectory calculations, based on present measurements of drop-burning rates, these findings suggest significant effects of separated flow in combusting HAN-based monopropellant sprays.
\end{abstract}

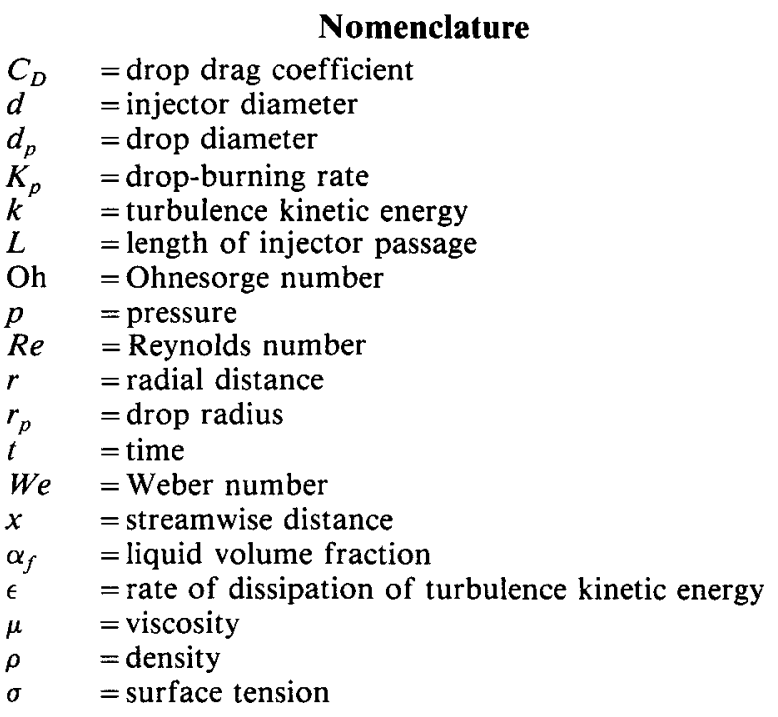

Subscripts

$c \quad=$ centerline value

$f \quad=$ liquid-phase property

$g \quad=$ gas-phase property

$p \quad=$ drop property

$o \quad=$ injector exit condition

$\infty \quad=$ ambient condition

Superscripts

$=$ time-averaged property

$=$ Favre-averaged property

\section{Introduction}

C OMBUSTING monopropellant sprays have applications to regenerative liquid-propellant guns, throttleable thrusters, and underwater propulsion systems. The objective of the

Presented as Paper 89-0049 at the AIAA 26th Aerospace Sciences Meeting, Reno, NV, Jan. 11-14, 1989; received Jan. 14, 1989; revision received April 30, 1989. Copyright (C) 1989 by the American Institute of Aeronautics and Astronautics, Inc. All rights reserved.

${ }^{*}$ Graduate Assistant. Aerospace Engineering.

†Professor, Aerospace Engineering. Fellow AIAA. present study was to experimentally investigate aspects of monopropellant spray combustion, seeking to extend earlier theoretical results obtained in this laboratory. ${ }^{1-3}$ Two spray processes were considered: 1) the combustion properties of individual drops supported in combustion gas environments at pressures of $0.2-7.0 \mathrm{MPa}$ and 2) the structure of pressureatomized combusting sprays in combustion gas environments at pressures of 3-9 $\mathrm{MPa}$. The measurements were used to assess the importance of separated-flow phenomena within pressure-atomized combusting monopropellant sprays, i.e., effects of finite velocities and transport rates between the phases. Similar to our earlier work,,$^{1-3}$ the investigation was limited to a hydroxyl-ammonium nitrate (HAN)-based monopropellant (LGP 1845) which is of interest for several highpressure monopropellant combustion systems.

Individual drop-burning rates are needed to help understand the properties of combusting monopropellant sprays. Earlier studies relevant to drop-burning rates of HAN-based monopropellants have included measurements of strandburning rates ${ }^{4-6}$ and the burning rates of individual drops in heated environments. ${ }^{7-10}$ McBratney ${ }^{4,5}$ measured strandburning rates of HAN-based monopropellants at pressures of 7-100 MPa. The propellant liquid was gelled with two weight percent Kelzan in order to stabilize turbulent-like disturbances of the liquid surface that are normally encountered during strand combustion tests at high pressures. The strand-burning rates of gelled LGP 1845 were high (approximately $20 \mathrm{~mm} / \mathrm{s}$ ) and the pressure dependence was relatively weak (approximately $\mathrm{p}^{0.1}$ ). A frothy region was observed at low pressures, where the thermal disturbance of the combustion wave extends an appreciable distance into the unburned propellant suggesting significant reaction in the condensed phase for these conditions. These results are valuable; however, the use of a gelling agent raises questions concerning its influence on the process. Vosen ${ }^{6}$ measured strand-burning rates of two ungelled HAN-based monopropellants, LGP 1846 and a 9.1 molar solution of HAN and water at pressures of 7-30 MPa. The burning rates of both propellants were very high, 100-25 $\mathrm{mm} / \mathrm{s}$, and liquid surfaces were clearly disturbed, indicative of turbulentlike instability of burning liquid strands normally seen at high pressures. Therefore, these results are difficult to interpret to find the fundamental combustion properties of the propellants.

Zhu and Law" studied the drop combustion properties of LGP 1845 and other HAN-based propellants in combustion gases at $1170 \mathrm{~K}$ and $1 \mathrm{~atm}$. The drops were observed to heat up 
with no radius change at first, then to gasify from the surface for a time (with surface regression rates of approximately $\mathbf{0 . 2}$ $\mathrm{mm} / \mathrm{s}$ ), and finally, to burst when the drop diameter had decreased by roughly $15 \%$. Beyer ${ }^{8,9}$ and Beyer and Teague ${ }^{10}$ studied the combustion of LGP 1846 drops supported in nitrogen at temperatures of $570-920 \mathrm{~K}$ and pressures of $0.1-8.2$ MPa. These observations yielded results similar to $\mathrm{Zhu}$ and law ${ }^{7}$ : after a heat-up time and a period of relatively slow surface gasification $(0.2 \mathrm{~mm} / \mathrm{s}$ at $730 \mathrm{~K}$ and $1 \mathrm{MPa})$, the drops then burst - particularly the larger drops. Both sets of drop experiments suggest that bulk liquid reaction and microexplosions may be important for combustion of HAN-based monopropellants, but drop environment temperatures were low in comparison to the adiabatic combustion temperature of the monopropellant, (approximately $2150 \mathrm{~K}$ ). Therefore, the drops may not have ignited in a manner representative of spray combustion.

Earlier theoretical work in this laboratory addressed liquidsurface and spray properties of combusting HAN-based monopropellants. ${ }^{1-3}$ Analysis of liquid-surface properties indicated relatively high liquid-surface temperatures (in the range $800-1050 \mathrm{~K}$ for pressures greater than $10 \mathrm{MPa}$ ) and unusually high pressures for the liquid surface to reach its thermodynamic critical point ( $250 \mathrm{MPa}$ with an estimated uncertainty of $50 \%))^{1,2}$ The high temperatures of the liquid surface provide greater potential for significant effects of chemical reaction in the bulk liquid than most monopropellants helping to explain observations of microexplosions reported in Refs. 7-10. Furthermore, the high critical combustion pressure also implies that spray combustion of HAN-based monopropellants involves subcritical combustion with a drop-containing combusting spray for most applications.

The earlier analysis of combusting HAN-based monopropellant sprays, ${ }^{1,3}$ was based on the locally homogeneous flow (LHF) approximation of multiphase flow theory, i.e., the assumption that velocity differences between the phases are negligible at each point in the flow ${ }^{11-13}$ and the thin laminar flamelet approximation of turbulent premixed flame theory proposed by Bray. ${ }^{14,15}$ Turbulent mixing was estimated using a Favre-averaged $k-\epsilon$ turbulence model with empirical constants established from measurements in noncombusting variabledensity round jets. ${ }^{16,17}$ However, the constants used are very similar to early proposals based on constant-density turbulent flows. ${ }^{18}$ The performance of the analysis was evaluated using the measurements of Birk and Reeves ${ }^{19}$ for pressure-atomized combusting LGP 1846 sprays at pressures of 6-8 MPa. There was encouraging agreement between predictions and measurements; however, predictions were very sensitive to the degree of flow development at the injector exit which was not known very well. Therefore, this assessment was not definitive. Later measurements of noncombusting pressure-atomized sprays by Ruff et al. ${ }^{13}$ established the strong sensitivity of spray properties to the degree of flow development at the jet exit and observed reasonably good performance of LHF predictions in the dense-spray region (liquid volume fractions greater than $0.2)$ near the injector exit for atomization breakup. However, these measurements also disclosed significant deficiencies of the LHF approximation for other breakup regimes and in the dilute portion of the spray - the last observation being in general agreement with other recent evaluations of the LHF approach for dilute sprays. ${ }^{11,12}$

The present investigation sought to extend past work concerning both drop and spray combustion of HAN-based monopropellants. Drop combustion was observed using an approach similar to Beyer and Teague ${ }^{10}$ for pressures of $0.2-7$ $\mathrm{MPa}$; however, the drop environment more closely matched the gas temperature of a combusting monopropellant spray. Measurements of spray properties were undertaken seeking to confirm the measurements of Birk and Reeves, ${ }^{19}$ while considering a broader range of experimental conditions at pressures of 3-9 MPa. The new spray measurements-in conjunction with both LHF predictions and drop trajectory calculations based on the present drop-burning rate measurements-were used to assess the importance of separated-flow phenomena for these flows.

\section{Drop Combustion}

\section{Experimental Methods \\ Apparatus}

Figure 1 is a sketch of the drop combustion test apparatus. The supported-drop technique was used with the drops ex-

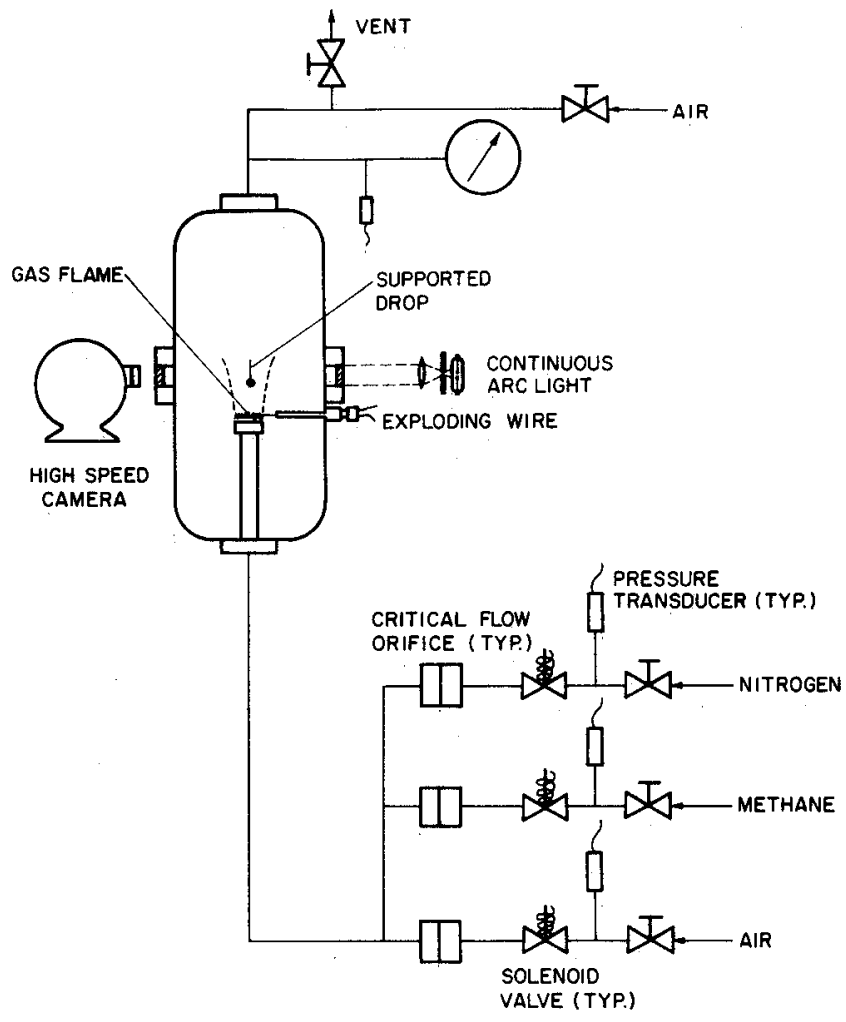

Fig. 1 Sketch of drop combustion apparatus.

Table 1 Combustion product properties ${ }^{\mathrm{a}}$

\begin{tabular}{|c|c|c|c|c|}
\hline \multirow[b]{2}{*}{ Mixture } & \multirow[b]{2}{*}{ LGP $1845^{b}$} & \multicolumn{3}{|c|}{ Test environment gases } \\
\hline & & Burner $1^{d}$ & Burner $2^{\mathrm{d}}$ & Spray \\
\hline Temperature $(\mathrm{K})$ & 2150 & 2295 & 2230 & 2790 \\
\hline \multicolumn{5}{|c|}{ Composition ( $\%$ by volume) ${ }^{\mathrm{c}}$} \\
\hline $\mathrm{H}_{2} \mathrm{O}$ & 69.2 & 18.8 & 18.0 & 19.8 \\
\hline $\mathrm{CO}_{2}$ & 12.9 & 9.1 & 8.9 & -1 \\
\hline $\mathrm{N}_{2}$ & 17.4 & 71.2 & 72.6 & 38.3 \\
\hline $\mathrm{Ar}$ & - - & - - & - & 40.9 \\
\hline
\end{tabular}

${ }^{a}$ Computed for $10 \mathrm{MPa}$ using the Gordon and $\mathrm{McBride}^{20}$ algorithm, but effects of dissociation are small.

${ }^{\mathrm{b}}$ Reactant composition ( $\%$ by mass): HAN, 63.2, TEAN, 20; and $\mathrm{H}_{2} \mathrm{O}, 16.8$

${ }^{c}$ Major species only. Minor species include $\mathrm{CO}, \mathrm{H}_{2}, \mathrm{NO}, \mathrm{OH}$, and $\mathrm{O}_{2}$

d Volume flow rate of burner gases (cold) of $6.28 \times 10^{-5} \mathrm{~m}^{3} / \mathrm{s}$. 


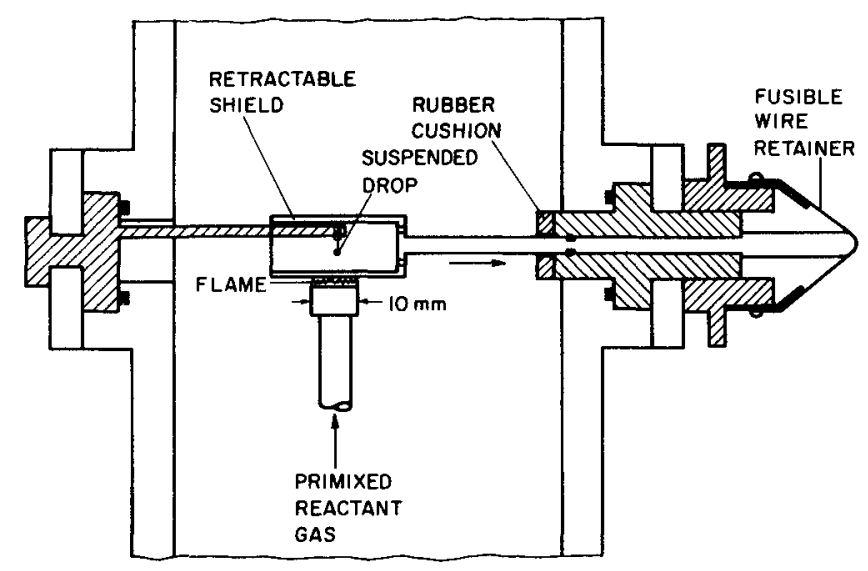

Fig. 2 Sketch of drop support assembly.

posed to gases in the postflame region of a premixed burner that was operated within a pressure vessel. The pressure vessel had an inside diameter and length of 130 and $430 \mathrm{~mm}$ and was fitted with two quartz windows ( $25-\mathrm{mm}$ diam) so that the drops could be observed.

The premixed burner had a diameter of $10 \mathrm{~mm}$ with a stainless steel screen (wire diameter of $0.17 \mathrm{~mm}, 2000$ wires $/ \mathrm{m}$, square pattern) to help stabilize the flame. The gas flow rates of the premixed burner were metered and controlled with critical flow orifices and pressure regulators. Burner operating times were short, just sufficient to stabilize the premixed flame and to complete the drop combustion test. Burner gas flows were initiated and terminated with solenoid valves while the burner was ignited with an exploding wire. The pressure rise of the chamber (measured with a pressure transducer) was small in the period when the burner was operating approximately $5 \%$; therefore, the chamber pressure was set by backfilling it with air. The properties of the postflame region of the premixed burner roughly approximated the temperatures of constant-pressure adiabatic combustion of the monopropellant, but contained significantly lower concentrations of water vapor. See Table 1 for the combustion product properties of LGP 1845 and the burner gases (denoted burner 1 and 2).

The drop support assembly is illustrated in Fig. 2. The drops were mounted on quartz fibers before the chamber was pressurized. The fibers were $50-150 \mu \mathrm{m}$ in diameter with the bottom end of the fiber flame polished to a bead having a somewhat larger diameter to help support the drop. The drop was surrounded with a retractable shield to protect it from transients when the premixed flame was ignited. Once the premixed flame was stabilized, the shield was rapidly retracted by fusing its wire retainer so that the unbalanced pressure force on the shield forced it to one side of the pressure vessel where it was stopped by a rubber cushion. In general, the time required for the shield to move across the burner was less than $10 \%$ of the drop lifetime in the burner gases.

\section{Instrumentation}

Drop diameter was measured as a function of time using shadowgraph motion picture photographs. The arrangement of the illuminating and camera system is illustrated in Fig. 1. The drops were backlighted by a continuous arc source using a condensing lens to direct the light to a diffusion screen located at one of the windows. The shadowgraphs were recorded using a motion picture camera operating at roughly 1000 pictures per second, which incorporated an internal timing marker.

\section{Results and Discussion}

Some typical plots of drop diameter as a function of time are illustrated in Fig. 3. Results of two tests (each) at pressures of 0.51 and 2.1 MPa are shown for initial drop diameters in

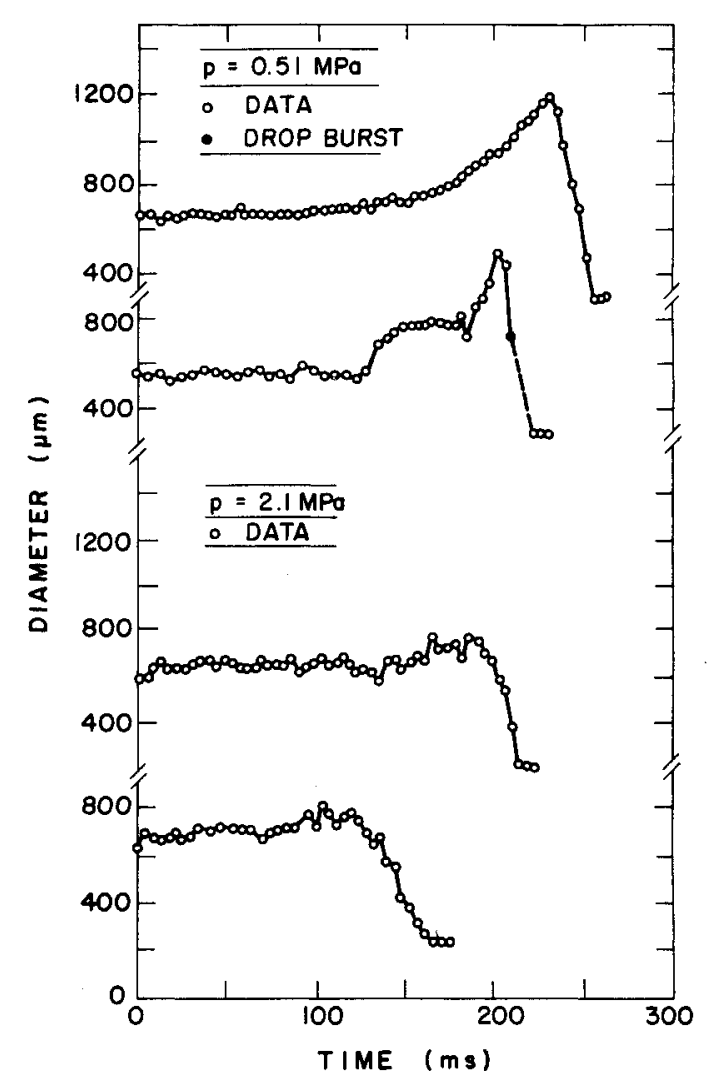

Fig. 3 Drop-diameter histories at 0.51 and 2.1 MPa.

the range $580-650 \mu \mathrm{m}$. The beads on the quartz fibers to help support the drops had diameters of 300 and $200 \mu \mathrm{m}$ for pressures of 0.51 and $2.1 \mathrm{MPa}$, respectively. The motion of the retractable shield disturbed the premixed flame causing it to flap for a time even after the shield had cleared the burner exit; therefore, the time when the drop was actually submerged in the postflame gases was uncontrolled and variable and the origin of these plots is somewhat arbitrary.

The results illustrated in Fig. 3 for a pressure of $0.51 \mathrm{MPa}$ are typical of behavior at low pressures. After a somewhat variable delay, probably influenced by flapping of the burner flame as noted earlier, the drops would begin to swell due to the development of bubbles within the liquid. The bubbles would periodically burst carrying off some of the liquid. Occasionally, bursting of a bubble was severe enough to either carry off all of the liquid or to cause the drop to fall from its support similar to the one example illustrated in Fig. 3. Thus, internal reaction and bursting with some mechanical removal of liquid caused by bursts appears to be the main mechanism for the reduction of drop diameter at low pressures.

The degree of drop swelling, due to the presence of bubbles in the bulk liquid, and the severity of drop bursting progressively decreased as the pressure was increased. The results illustrated in Fig. 3 for a pressure of $2.1 \mathrm{MPa}$ are typical of high-pressure conditions. These conditions exhibited some degree of internal bubble formation; however, effects of bubbles bursting were relatively mild, and complete bursting of bubbles was not observed at pressures of $2.1 \mathrm{MPa}$ and higher.

Reduced effects of internal bubbles at high pressures appear to be largely caused by increased gas density so that a given degree of bulk liquid reaction yields a lower volume of gas: this reduces bubble sizes and growth rates which tends to reduce the severity of bursting phenomena. Counter to this is the fact that liquid-surface temperatures tend to increase with increasing pressure for the present range of conditions (reaching a maximum at roughly $25 \mathrm{MPa}$ ): this is expected to increase rates of bulk liquid reaction. ${ }^{1,2}$ 
The time period of drop swelling, or relatively constant drop diameters, was irregular due to uncertainties concerning the time when the drop was submerged in the combustion gas environment. However, the period when the drop diameter decreased was analyzed to obtain effective drop-burning rates. Plots of drop diameter as a function of time in the period where the drop diameter is decreasing are illustrated for the present test conditions in Fig. 4. The origins of these plots are arbitrary since the data has been plotted to overlap in the region where the drop diameter is decreasing. In addition, conditions where the drops burst completely at low pressures have been excluded. Results at low pressures show wide variations due to significant effects of bubble swelling and bursting, but the diameter traces become more regular and repeatable at high pressures. These data were fitted to determine effective burning rates for the drops $K_{p}=-d r_{p} / d t$. The resulting fits are also illustrated in Fig. 4.

Present effective burning rates are plotted as a function of pressure in Fig. 5. These results are for drop diameters in the range $300-1200 \mu \mathrm{m}$ and include effects of both internal reaction forming bubbles which burst, mechanically removing some liquid, as well as conventional gasification at the surface of the drop. This combination of effects causes the effective burning rate to be highest at the lowest pressure, where bursting dominates the process, and then to show relatively little change with pressure over most of the region considered during present tests. The strand-burning results of McBratney ${ }^{4,5}$ and Vosen ${ }^{6}$ are also illustrated in Fig. 5. The present results are a crude extension of McBratney's ${ }^{4,5}$ measurements of gelled propellants at higher pressures. The results of Vosen ${ }^{6}$ are much higher than the rest of the measurements because of effects of liquid-surface disturbances of burning liquid strands at high pressures noted earlier.

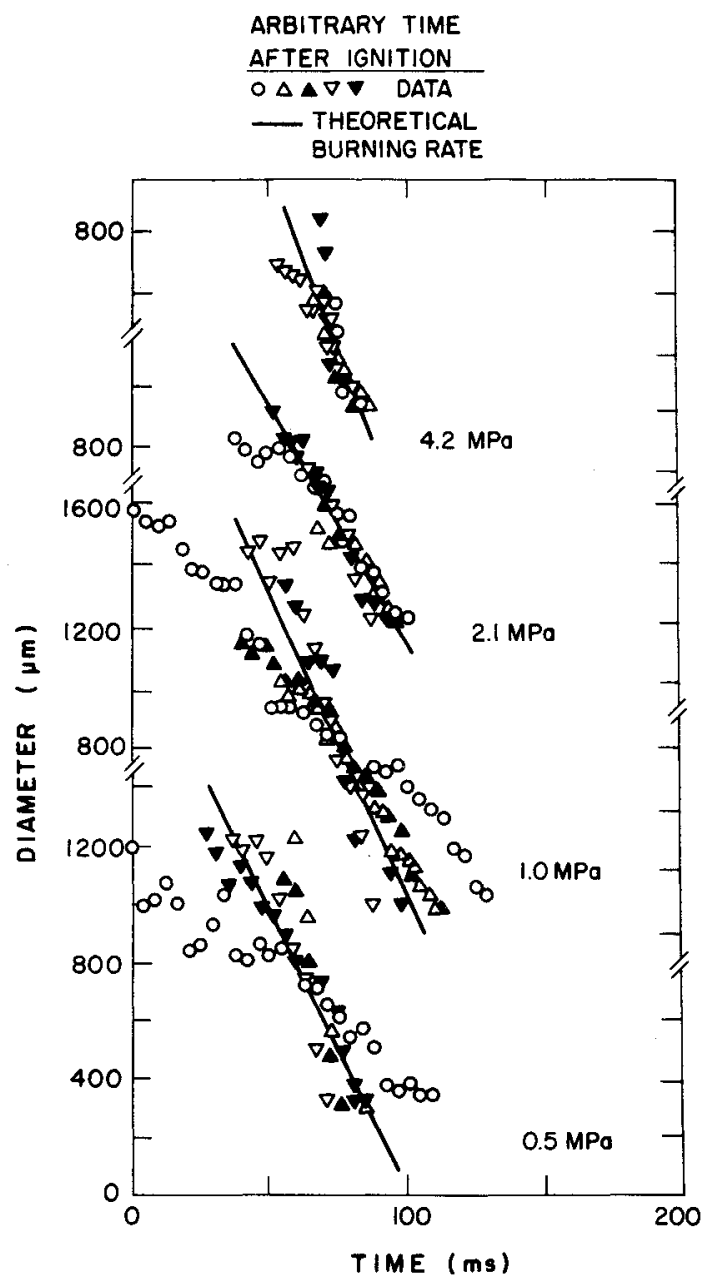

Fig. 4 Drop-diameter histories in the combustion period.

\section{Spray Combustion}

Experimental Methods

Apparatus

The present spray combustion test apparatus was similar to the arrangement used by Birk and Reeves. ${ }^{19}$ A sketch of the apparatus appears in Fig. 6. The experiments were conducted in the same chamber as the drop combustion tests. The combustion gas environment was produced by filling the chamber with a combustible mixture and then igniting it with two sparks to achieve the combustion gas properties summarized in Table 1 (denoted spray). The pressure of the spray tests was adjusted by varying the initial pressure of the combustible gas mixture since combustion of this gas approximated a constant volume process. The combustible gas mixture had adiabatic temperatures that were somewhat greater than the adiabatic constant-pressure combustion temperature of the monopropellant, but that were still within the range of conditions en-

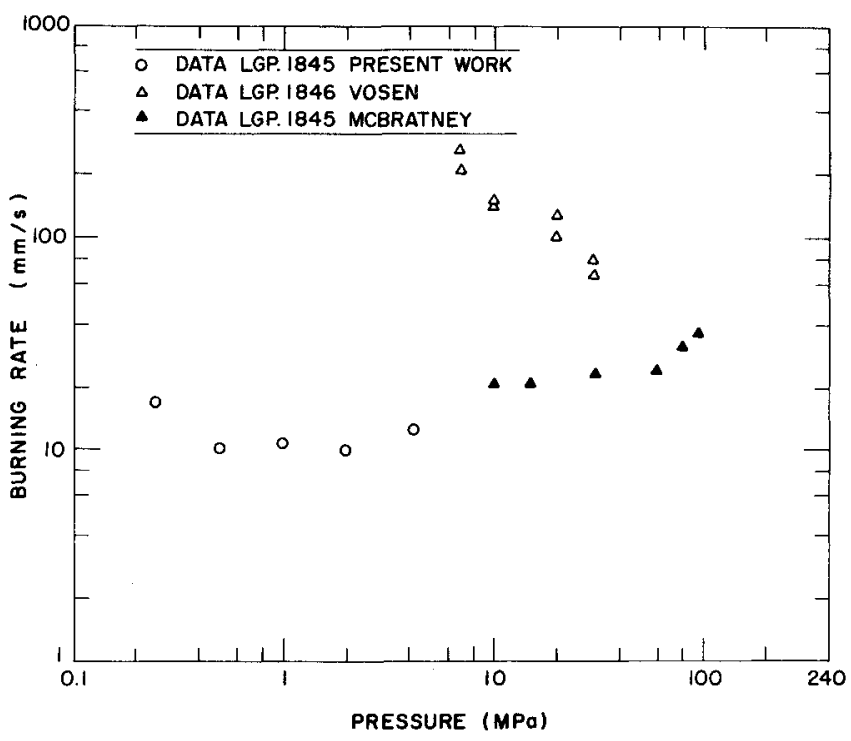

Fig. 5 Apparent drop-burning rates as a function of pressure.

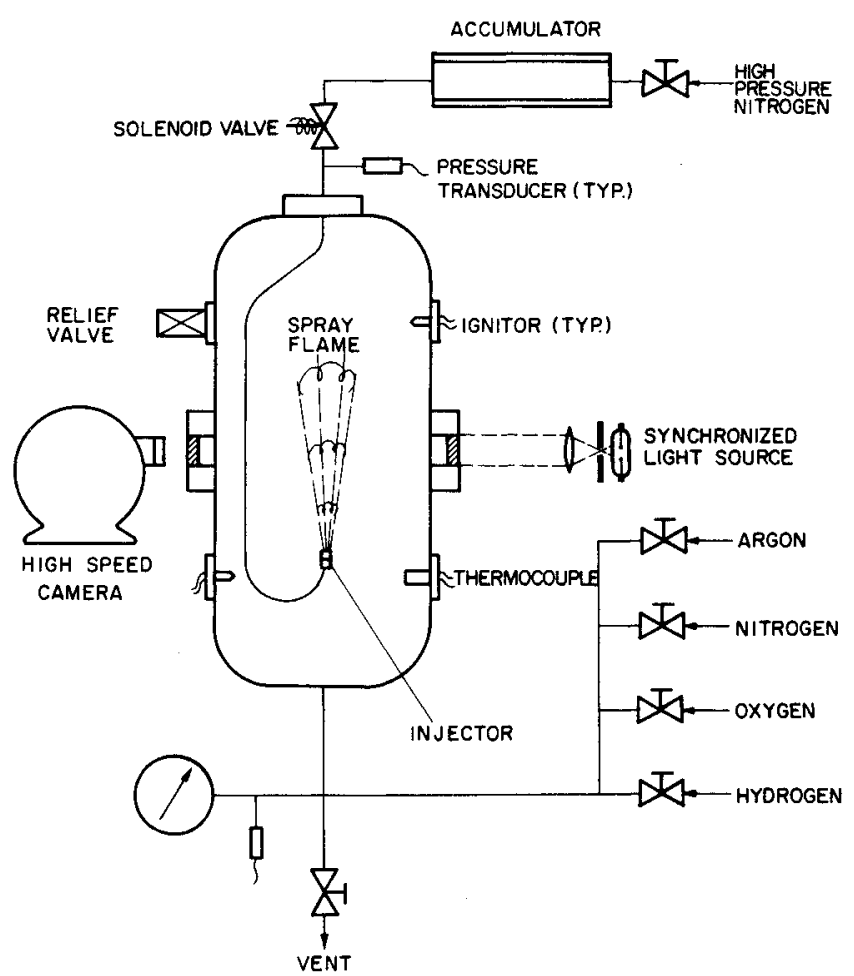

Fig. 6 Sketch of spray combustion apparatus. 
countered in liquid propellant guns due to temperature increases caused by constant-volume combustion. Heat losses from the combustion products also tended to reduce temperatures to the range of adiabatic constant-pressure combustion of the propellant based on chamber pressure measurements.

The spray was pressure atomized using injectors having exit diameters of $0.31,0.58,1.08$, and $1.17 \mathrm{~mm}$. The inlet of the injectors had baffles to control any swirl in the liquid and smooth entries to reduce effects of cavitation. Injectors having length-to-diameter ratios of 2,17 , and 42 were considered since earlier work indicated that the degree of flow development at the injector exit influenced spray-mixing properties. $^{2,3,13}$ The injectors were directed vertically upward.

A test was run by placing a propellant sample (3-4 $\mathrm{ml}$ ) in the fuel delivery tube and filling the injector passage up to its exit. A cap was then placed over the exit to prevent gas inflow when the chamber was filled with the combustible gas mixture and further pressurized as this gas burned. The propellant flow was initiated by venting nitrogen from an accumulator into the fuel delivery tube by opening a solenoid valve. Once the pressure of the propellant was greater than the chamber pressure, the cap popped off, and the resulting propellant flow generated a spray in the hot gas mixture. The process ended when all the propellant was consumed. The injector passage continued to be purged by the nitrogen flow from the accumulator for a time hefore the accumulator flow was ended.

\section{Instrumentation}

The combusting sprays were observed using motion picture shadowgraphs as illustrated in Fig. 6. Backlighting was provided by a flash lamp source, approximately $1 \mu$ s flash duration, which was synchronized with the camera; therefore, the image of the spray was effectively stopped on the film. The shadowgraphs were recorded with a $16-\mathrm{mm}$ high-speed camera operating at roughly 1000 pictures per second using Tri-X negative film. The camera optics yielded a field of view having a diameter of $25 \mathrm{~mm}$; therefore, it was necessary to adjust the position of the injector to observe the full length of the liquidcontaining region.

The present monopropellant does not produce particulates when burned, and gas temperatures are relatively uniform in monopropellant spray flames; therefore, the boundaries of the spray were reasonably well defined-similar to past measurements of Birk and Reeves. ${ }^{19}$ A typical shadowgraph photograph from the present tests is illustrated in Fig. 7 (this is a composite photograph due to the limited field-of-view of the camera). The background is somewhat mottled due to turbulent thermal boundary layers on the windows; however, these disturbances could be readily separated from the spray. The films were analyzed to yield mean and fluctuating timeaveraged liquid volume fractions. Dark zones were assigned to unburned liquid reactant and light zones to gaseous combus- tion products. For each test, 10-30 frames had sufficient contrast for analysis during the steady flow portion of the spray combustion process. Separating dark and light zones was somewhat subjective; and since the measurements correspond to line-of-sight projections, they are biased downstream and radially outward from correct point measurements of mean and fluctuating liquid volume fractions. Predictions were analyzed to estimate the line-of-sight biases as discussed in the next section.

\section{Test Conditions}

Test conditions for the spray-combustion measurements are summarized in Table 2. Most of the injector flows correspond to fully developed flow at the injector exit, which corresponds to turbulent pipe flow. Injection velocities were in the range $49-65 \mathrm{~m} / \mathrm{s}$; these conditions correspond to the atomization breakup regime, i.e., a drop-containing shear layer begins to develop at the liquid surface immediately at the injector exit. ${ }^{12,13}$

\section{Theoretical Methods}

Present measurements were compared with predictions based on the approach developed earlier in this laboratory. ${ }^{1,3}$ Drop-trajectory calculations were also carried out in order to help assess effects of separated-flow phenomena. Both methods of prediction are described in the following.

\section{Spray Predictions}

The main features of the spray-combustion model will be described only briefly in the following; original sources should be consulted for details.

The model involves use of the LHF approximation of multiphase flow theory ${ }^{1-13}$ and the thin laminar flamelet approximation of premixed turbulent flame theory. ${ }^{14,15}$ Turbulent mixing was treated using a Favre-averaged turbulence model. ${ }^{14-17}$ This approach provides a useful limit where both multiphase and chemical-reaction phenomena are controlled by turbulent mixing, which minimizes the empiricism needed

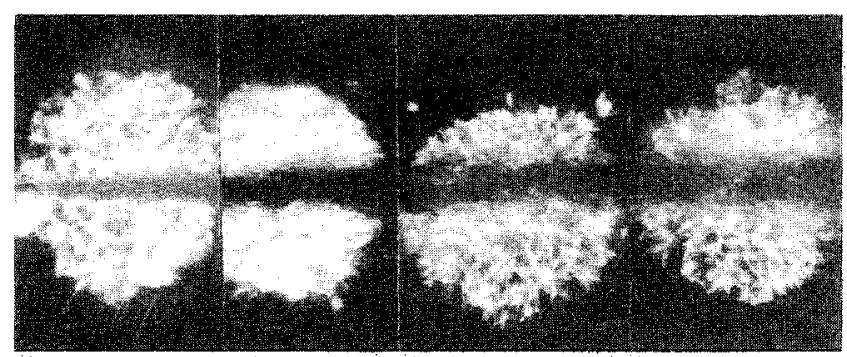

Fig. 7 Shadowgraph photograph of the combusting monopropellant spray: injector diameter $=0.58 \mathrm{~mm}$, ambient pressure $=3.19 \mathrm{MPa}$, injector pressure drop $=2.07 \mathrm{MPa}$, and fully developed flow.

Table 2 Summary of combusting spray test conditions

\begin{tabular}{crccccccc}
\hline \hline $\begin{array}{c}\text { Diameter } \\
(\mathrm{mm})\end{array}$ & $L / d$ & $\begin{array}{c}\text { Flow } \\
\text { type }\end{array}$ & $\begin{array}{c}\text { Ambient } \\
\text { pressure } \\
(\mathrm{MPa})\end{array}$ & $\begin{array}{c}\text { Pressure } \\
\text { drop } \\
(\mathrm{MPa})\end{array}$ & $\begin{array}{c}\text { Injector } \\
\text { velocity } \\
(\mathrm{m} / \mathrm{s})^{\mathrm{b}}\end{array}$ & $R e^{\mathrm{c}}$ & $\mathrm{Oh}^{\mathrm{d}}$ & $W e_{f}^{\mathrm{e}}$ \\
\hline $\begin{array}{c}\text { Radial measurements: } \\
1.17\end{array}$ & 17 & FDF & 3.11 & 2.02 & 52.7 & 12600 & 0.021 & 70700 \\
1.17 & 17 & FDF & 7.07 & 1.79 & 49.3 & 11800 & 0.021 & 62400 \\
1.17 & 17 & FDF & 9.10 & 1.81 & 49.7 & 11900 & 0.021 & 63300 \\
1.08 & 2 & SF & 6.83 & 1.93 & 51.4 & 11400 & 0.022 & 62200 \\
0.58 & 42 & FDF & 3.19 & 2.07 & 53.2 & 6300 & 0.030 & 35800 \\
0.58 & 42 & FDF & 6.15 & 2.76 & 61.6 & 7300 & 0.030 & 47900 \\
& & & & & & & & \\
Axial measurements: & & & & & & \\
0.58 & 42 & FDF & 3.22 & 2.33 & 56.6 & 6700 & 0.030 & 40400 \\
0.58 & 42 & FDF & 6.16 & 1.81 & 49.5 & 5900 & 0.030 & 30900 \\
0.58 & 42 & FDF & 8.99 & 2.14 & 54.3 & 6400 & 0.030 & 37100 \\
0.31 & 42 & FDF & 6.51 & 3.05 & 64.8 & 4000 & 0.041 & 27800 \\
\hline
\end{tabular}

${ }^{\mathrm{a}} \mathrm{FDF}=$ fully developed flow; $\mathrm{SF}=$ slug flow; ${ }^{\mathrm{b}}$ Unity flow coefficient; ${ }^{\mathrm{c}} \mathrm{Re}=\rho_{\mathrm{f}} \mathrm{u}_{\mathrm{o}} \mathrm{d} / \mu_{\mathrm{f}}, \mu_{\mathrm{f}}=0.0071$ $\mathrm{kg} / \mathrm{ms} ;{ }^{\mathrm{d}} \mathrm{Oh}=\rho_{\mathrm{f}} / \sqrt{\rho_{\mathrm{f}}} \mathrm{d} \sigma, \sigma=0.0669 \mathrm{~kg} / \mathrm{s}^{2} ;{ }^{\mathrm{e}} \mathrm{W} e_{f}=\rho_{f} u_{o}{ }^{2} d / \sigma$; 
for predictions, e.g., initial drop-size and velocity distributions, chemical-kinetic properties, etc., are not needed to define the problem. The main limitation of the LHF approximation is that its use generally tends to overestimate the rate of development of sprays, particularly in dilute-spray regions far from the injector exit. ${ }^{11-13}$ However, Ruff et al. ${ }^{13}$ find that the LHF approach using the present turbulent-mixing model provided reasonably good estimates of the mixing properties of the near-injector, dense-spray region of nonevaporating pressure-atomized sprays in the atomization breakup regimeconditions that are representative of present tests.

The thin laminar flamelet approximation implies that heterogeneous monopropellant flames cover all liquid surfaces. Except for very near the liquid surface, the liquid is at the same state as in the injector; whereas beyond the outer edge of the thin flame the gas has uniform properties equivalent to the adiabatic flame conditions noted in Table 1. Under the LHF approximation, relative velocities between the phases (slip) are neglected.

Other major assumptions of the calculations are 1) steady (in the mean) axisymmetric flow with no swirl; 2) low Mach numbers with negligible potential and kinetic energy changes and negligible viscous dissipation; 3 ) boundary-layer approximations apply; 4) negligible effects of radiant energy exchange; 5) equal exchange coefficients of all species and heat; and 6) high Reynolds numbers so that laminar transport is negligible in comparison to turbulent transport. Justification of these assumptions is presented in Refs. 1 and 3 .

Under these assumptions, flow properties can be found by solving governing equations for conservation of mass, momentum, and reaction progress variable in conjunction with second-order turbulence model equations for turbulence kinetic energy and its rate of dissipation. ${ }^{14,15}$ The formulation, all empirical constants used in the turbulence model, and the method of solution can be found in Ref. 3.

The predictions were also used to estimate potential effects of line-of-sight biasing on the measured distributions of liquid-volume fractions using a stochastic approach developed for radiation calculations in this laboratory. ${ }^{21}$ Knowing the time-averaged probability density function of the reaction progress variable along paths through the flow, the reaction progress variable was simulated for a series of statistically independent eddies along the path. Counting the presence of any liquid in the path as a condition which would block the light, giving a dark image on the film, yielded estimates of timeaveraged mean and fluctuating liquid volume fractions for the path. This procedure has not been calibrated using known flows; however, it does provide at least a qualitative indication of potential effects of line-of-sight bias.

\section{Drop-Trajectory Analysis}

Direct assessment of the approximations of the LHF approach for the monopropellant sprays was undertaken using drop-trajectory calculations, similar to the approach used by Shearer et al. ${ }^{22}$ and Mao et al. $^{23}$ for nonpremixed spray flames. These calculations were limited to drops moving along the axis of the spray. The drops were assumed to be always in contact with the gas phase which was taken to have the properties summarized in Table 1. Estimates of the gas velocities along the axis were obtained from the LHF predictions.

Drop-trajectory calculations were limited to deterministic analysis and ignored effects of turbulence/drop interactions; therefore, mean gas velocities from the LHF analysis were used in the governing equation for drop motion. Drops were assumed to be surrounded by gas immediately at the injector exit ignoring the all-liquid core present in these sprays. ${ }^{13} \mathrm{Ef}$ fects of drop heat-up were also ignored; the drop radius was assumed to decrease throughout the entire trajectory at 10 $\mathrm{mm} / \mathrm{s}$-based on the results of Fig. 6 for the present test range. This high burning rate implies that the decomposition flame is located near the drop surface, well within the boundaries of the flowfield around the drop; therefore, gas-phase properties used to estimate drop drag were taken to be ambient gas properties, and effects of forced convection on drop burning rates were ignored. Similarly, eventual loss of the linear burning rate law of monopropellants $\left(K_{p}=-d r_{p} / d t\right.$ $=$ constant) for small drops, where effects of curvature become important, was also ignored. This is justified since present burning rate results and the evaporation constants observed by Zhu and $\mathrm{Law}^{7}$ and Beyer ${ }^{8}$ suggest that this transition would occur for very small drops, approximately $1 \mu \mathrm{m}$ in diameter. Other aspects of the analysis were similar to those Refs. 22 and 23: the flowfield around the drop was assumed to be quasisteady; virtual mass, pressure-gradient, Basset history, and gravitational forces were ignored; swelling of the drops was ignored; and drop drag was estimated using the standard drag correlation for solid spheres.

Under these assumptions, the governing equations of drop motion along the axis are as follows ${ }^{12}$ :

$$
\begin{gathered}
d x_{p} / d t=u_{p} \\
d d_{p} / d t=-2 k_{p} \\
d u_{p} / d t=-3 \rho g C_{D}\left|u_{p}-\bar{u}\right|\left(u_{p}-\vec{u}\right) /\left(4 d_{p} \rho_{p}\right)
\end{gathered}
$$

where

$$
\begin{gathered}
C_{D}=24\left(1+R e_{p}^{2 / 3} / 6\right) / R e_{p}, R e_{p} \leq 1000 ; \\
C_{D}=0.44, R e_{p}>1000
\end{gathered}
$$

The initial condition is $u_{p}=u_{o}, d_{p}=d_{p o}$ and $x_{p}=0$ at $t=0$. Equations (1-3) were integrated using a Runge-Kutta algorithm.

\section{Results and Discussion}

It was not possible to observe ignition from flame luminosity due to strong background lighting; however, ignition was readily identified from chamber pressure records. Typical pressure records, with and without propellant injection, are illustrated in Fig. 8. For the baseline test without propellant injection, chamber pressures decline continuously after the premixed gas has burned due to heat losses from the hotcombustion products to the cold-chamber walls. In contrast, the record with propellant injection exhibits a plateau region due to combustion energy release from the propellant in the period where it was flowing. Furthermore, injection of water or unignited monopropellant (not shown in Fig. 8) increased the rate of pressure decay in comparison to baseline conditions with no liquid injection since the spray rapidly quenched the hot-gas mixture. Based on these observations, it was possible

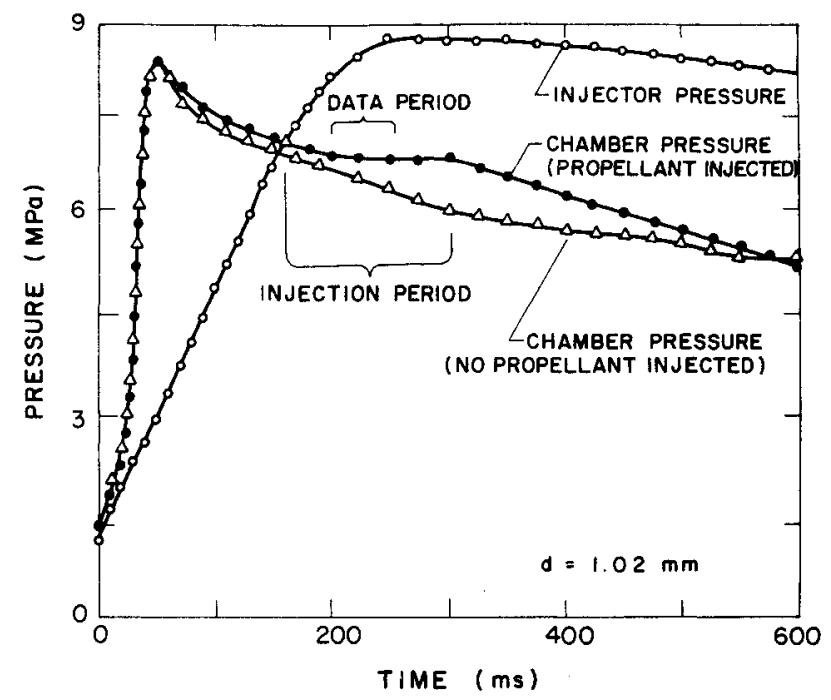

Fig. 8 Pressure-time records with and without propellant injection. 


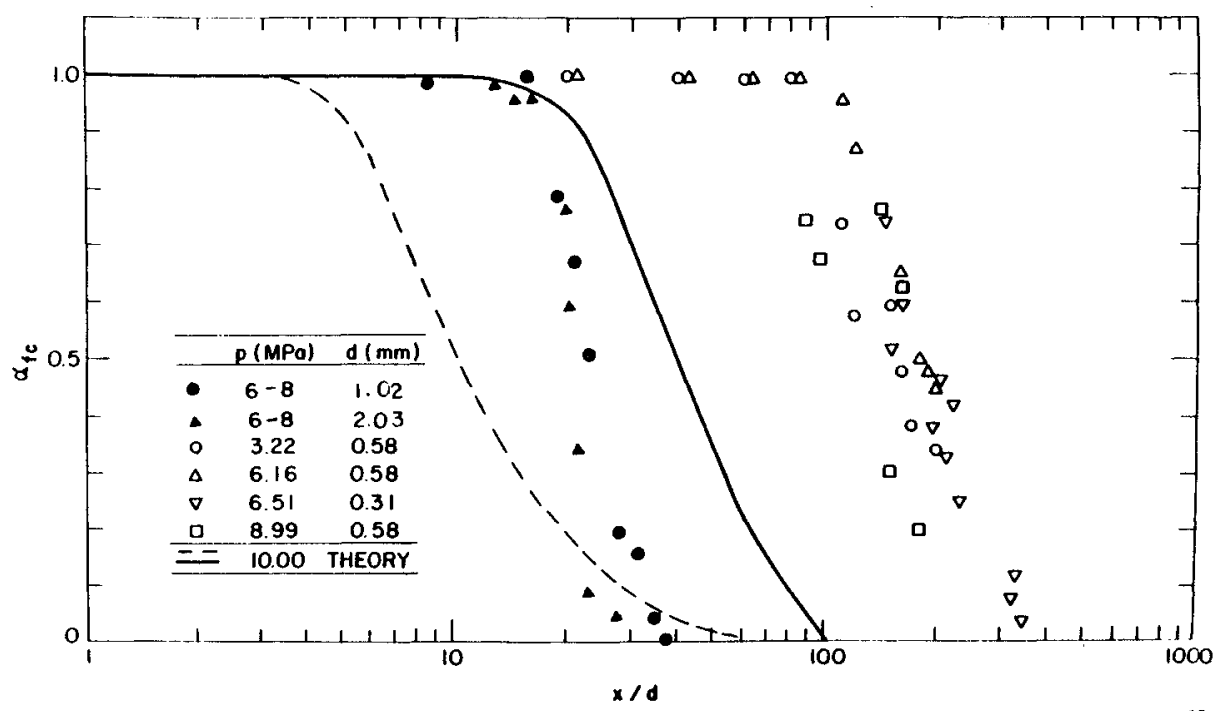

Fig. 9 Time-averaged liquid volume fractions along axis. Open symbols, present study; closed symbols, Birk and Reeves ${ }^{19}$; solid and dashed lines are predictions with and without line-of-sight bias correction.

to consistently ignite the propellant spray at pressures as low as $2.7 \mathrm{MPa}$ : the present measurements, however, were confined to pressures of 3-9 $\mathrm{MPa}$.

The measurement period is also illustrated in Fig. 8. Typically, measurements were begun roughly $50 \mathrm{~ms}$ after the instant when the injector pressure just exceeded the chamber pressure and injection began so that the injector pressure drop was high enough to reach the atomization breakup regime. Measurements were then made over a period of about $50 \mathrm{~ms}$, after which water vapor condensation on the windows reduced contrast to the point where the spray was hard to distinguish. Injector pressure drops varied somewhat during the period of measurements: conditions summarized in Table 2 are for the midpoint of the data period. The effect of variation of the pressure drop during the data period is probably not large, however, since changes in maximum injector pressure drops had little effect on observations within the atomization breakup regime.

Measured and predicted time-averaged liquid volume fractions along the axis $\tilde{\alpha}_{f c}$ are plotted as a function of normalized distance from the injector exit, $x / d$, in Fig. 9. Both present measurements and those of Birk and Reeves ${ }^{19}$ are shown on the plot. Predictions include direct values of $\bar{\alpha}_{f c}$ as well as results allowing for line-of-sight bias as noted earlier.

Test conditions used by Birk and Reeves ${ }^{19}$ were similar to present test conditions, except that injector $L / d$ was in the range 1.2-2.4, the injector inlet was not rounded (see Lee et al. $^{3}$ for a sketch of the injectors), and injector pressure drops were 1.5-2.0 times higher than the present study. The motion picture shadowgraphs of both investigations were obtained in a similar manner and were analyzed in this laboratory. Each set of experimental results also exhibits a significant degree of internal consistency and repeatability when plotted in the manner of Fig. 9. Finally, pressure traces indicated that measurements were obtained for combusting sprays for both studies. Nevertheless, present measurements exhibit a much longer liquid-containing region than those of Birk and Reeves, ${ }^{19}$ e.g., $\bar{\alpha}_{f_{c}}=0.5$ at $x / d$ roughly 150 and 25 for the two sets of measurements. There are a number of possible reasons for these differences. First of all, Birk and Reeves ${ }^{19}$ used a sharp injector inlet which could have caused cavitation in the injector passage, yielding a more finely atomized spray with a rapid rate of radial spread. Second, propellant flow rates per unit cross-sectional area of the combustion chamber were 20-100 times larger for the measurements of Birk and Reeves ${ }^{19}$ than the present measurements. This suggests higher recirculation flow velocities near the edge of the spray, increasing radial spread, and mixing rates as well. Next, Birk and Reeves ${ }^{19}$ did not employ a cap over the injector to prevent gas inflow as the chamber pressure increased during combustion $n f$ the premixed gas mixture; ingested gas would enhance atomization similar to a twin fluid injector-in fact, occasional sputtering of the injector flow was observed, which tends to support some degree of gas ingestion. Additionally, the injector used by Birk and Reeves ${ }^{19}$ did not have a flow straightener, and swirl induced in the injector flow passage could have resulted in unusually high radial spread rates; although their fuel-injection system only involved rectilinear motion and does not appear to be fundamentally prone to induce swirl. Finally, Birk and Reeves ${ }^{19}$ employed somewhat higher injector pressure drops which would be expected to yield smaller drop sizes in the spray; nevertheless, spray conditions for both investigations were in the atomization breakup regime. Furthermore, the pressure drop increase does not appear to be sufficient to explain the differences in Fig. 9 based on the relatively small effect of pressure-drop variations observed during the present investigation. In any event, extensive rechecking of measurements using the present injectors and test chamber could not reproduce the results of Birk and Reeves. ${ }^{19}$

Present measurements in Fig. 9 are roughly similar (in terms of $x / d)$ at all test conditions, with the downstream limit of the liquid-containing region at $x / d$ approximately 350 . Since these results involve a range of pressures and injector diameters, this behavior suggests a mixing-controlled process supporting the use of LHF analysis - a conclusion reached in Ref. 3 based on the measurements of Birk and Reeves. ${ }^{19}$ Closer examination of the data, however, reveals trends that suggest significant separated-flow effects. First of all, results for the $0.31-\mathrm{mm}$ diam injector consistently exhibit higher values of $\bar{\alpha}_{f c}$ at a particular $x / d$ than the $0.58-\mathrm{mm}$-diam injector. This is a separated-flow property since drop diameters are not strongly affected by injector diameters; whereas drops of a particular size must penetrate a certain distance in order to disappear: this results in a tendency for penetration distances $x$ to be constant for separated flows rather than $x / d .{ }^{11}$ Another effect is that $\vec{\alpha}_{f_{c}}$ at a particular $x / d$ is generally lower for a chamber pressure of $8.99 \mathrm{MPa}$ than for the other pressures considered for the 0.58 -mm-diam injector: this behavior parallels the effective burning rate results of Fig. 6 where drop-burning rates at $9 \mathrm{MPa}$ are higher than for pressures in the range 3-6 $\mathrm{MPa}$, all of which are roughly the same. The effect of pressure is still not very strong, however, in view of larger data scatter at 9 $\mathrm{MPa}$, which is caused by reduced shadowgraph contrast as pressures increase. A final effect is that use of long and short $L / d$ injectors yielded roughly the same results while mixing- 
controlled flows would result in much faster mixing rates for the long $L / d$ injector. ${ }^{13}$

Predictions illustrated in Fig. 9 are for fully developed flow at the injector exit, which corresponds to the bulk of present test conditions. Effects of ambient pressure, injector diameter, and injector Reynolds number had little effect on the predictions; therefore, only single lines are shown for results with and without the line-of-sight bias correction. Comparing predictions with and without the line-of-sight bias correction indicates significant effects of bias for intermediate values of $\bar{\alpha}_{f c}$; however, predictions of the downstream end of the liquidcontaining region are not strongly influenced by bias.

In view of the bias uncertainties, the predictions illustrated in Fig. 9 are in fair agreement with the measurements of Birk and Reeves. ${ }^{19}$ This observation prompted earlier enthusiasm about the value of the LHF and thin laminar flamelet approximations for predicting flows of this type. However, comparison of predictions with present measurements implies that use of the LHF approximation causes the rate of development of the spray to be substantially overestimated in agreement with most other evaluations of the LHF approximation for sprays. ${ }^{11-13}$

Radial profiles of time-averaged liquid volume fractions at various distances from the injector are illustrated in Fig. 10. All measurements shown in the figure were obtained during the present investigation. Predictions shown on the figure account for line-of-sight bias and are for fully developed flow at the injector exit. Similar to results along the axis, predictions were relatively independent of test conditions, and only a single line is shown for each streamwise position. Results ignor-

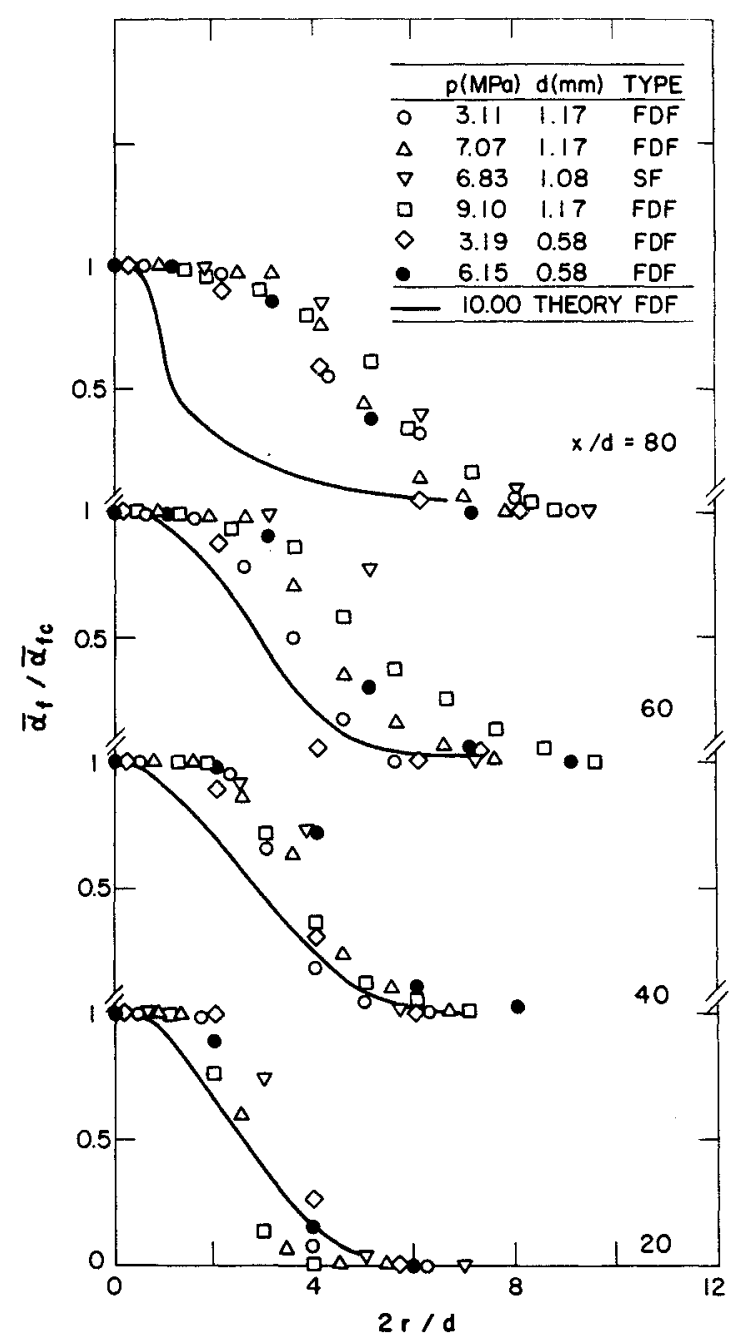

Fig. 10 Radial profiles of time-averaged liquid volume fractions. Predictions include line-of-sight bias correction. ing line-of-sight bias are narrower than the plots illustrated in Fig. 10; however, the outer extent of the liquid-containing region is about the same.

Similar to results along the axis, the measured radial profiles are crudely similar for all the test conditions when plotted in the manner of Fig. 10. In terms of $r / x$, the radial similarity variable of turbulent jets, the liquid-containing region extends to $0.05-0.07$, rather than 0.15 , which is a typical width based on scalar properties in turbulent jets. Predictions provide a fair estimate of flow widths near the injector exit but progressively fail with increasing distance from the injector exittending to over estimate the rate of development of the flow. This behavior is similar to other evaluations of the use of the LHF approximation for both nongasifying and gasifying sprays.

Drop-trajectory computations illustrated in Figs. 11 and 12 also support significant effects of separated flow. Drop velo-

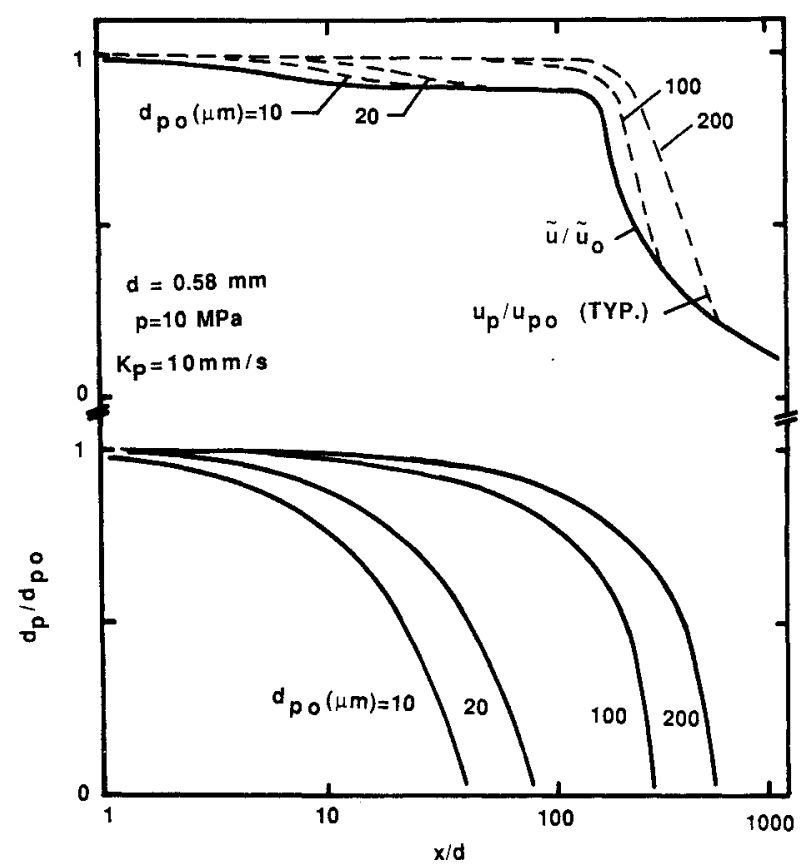

Fig. 11 Predicted drop properties along axis for a 0.58-mm injector diameter.

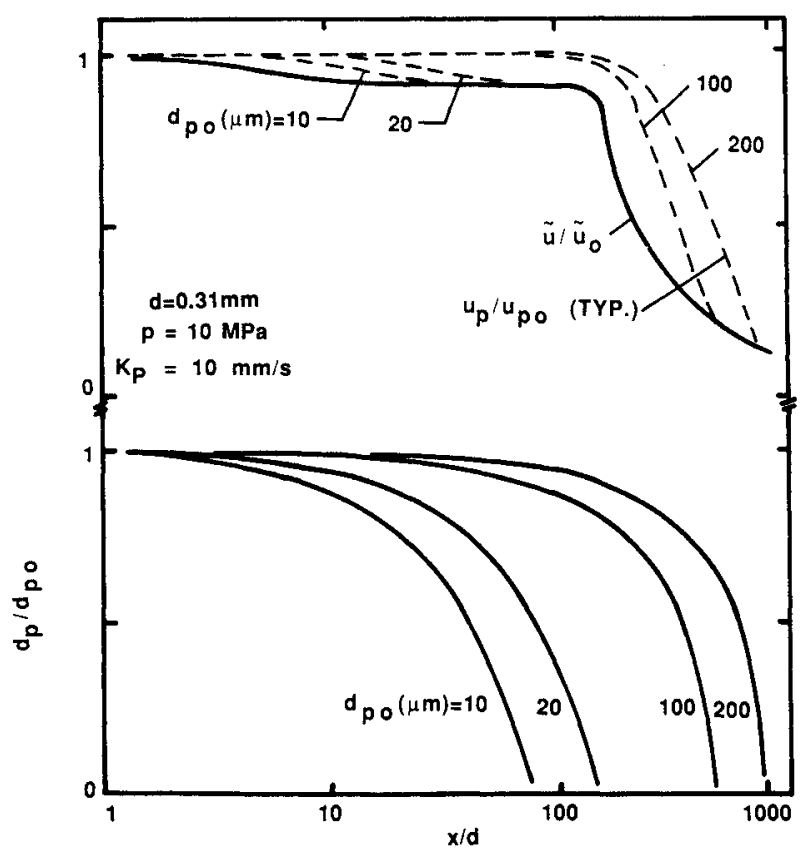

Fig. 12 Predicted drop properties along axis for a $0.31-\mathrm{mm}$ injector diameter. 
cities and diameters along the axis are plotted as a function of distance from the injector for injector diameters of 0.58 and $0.31 \mathrm{~mm}$ along with $\mathrm{LHF}$ velocity predictions. Results are shown for initial drop diameters of 10,20,100, and $200 \mu \mathrm{m}$. Limited measurements of drop-size distributions in the present sprays, using slide impaction at $x / d=150$ and 300 , indicated maximum drop diameters in the range 100-200 $\mu \mathrm{m}$; whereas drops much larger than $200 \mu \mathrm{m}$ would be subject to secondary breakup due to excessively high drop Weber numbers ${ }^{12}$; therefore, maximum drop sizes considered in Figs. 11 and 12 are representative of the maximum drop sizes probably present in the combusting sprays.

The LHF predictions illustrated in Figs. 11 and 12 exhibit a decay of velocity beyond the potential core-like region which is inversely proportional to distance-similar to single-phase jets. Due to the small injector diameters, this represents a rapid deceleration rate so that the larger drops overshoot the velocity of the continuous phase and only approach it again toward the end of their lifetime. Furthermore, LHF predictions indicate little liquid beyond $x / d=220$, where $\bar{\alpha}_{f c} \sim 10^{-4}$; whereas the drop-trajectory calculations show the larger drops passing well beyond this position. Finally, comparing the results of Figs. 11 and 12 shows that drops of a given size reach larger values of $x / d$ for the smaller injector diameter since rates of deceleration are faster, and the actual distance traveled for a particular value of $x / d$ is smaller for the smaller diameter injector. These trends are in general accord with the measurements illustrated in Fig. 9.

Taken together, the results of Figs. 9-12 suggest significant separated-flow effects for combusting HAN-based monopropellants over the present test range. In view of the relatively modest variation of burning rate with pressure seen in Fig. 6, the insensitivity of drop-drag properties to pressure ${ }^{11,12}$ and the relatively high critical combustion pressure of HAN-based monopropellants (ca. $250 \mathrm{MPa}^{1,2}$ ), it is likely that separatedflow phenomena are important for combusting HAN-based monopropellant sprays for most of their range of application.

\section{Conclusion}

The present study considered the combustion properties of the HAN-based monopropellant LGP 1845, both as drops and sprays, in combustion gas environments at pressures of 0.2-9 $\mathrm{MPa}$. The spray measurements and drop-trajectory calculations based on the present drop-burning rate measurements were used to evaluate predictions of spray properties based on the locally homogeneous flow and thin laminar flamelet approximations, due to Faeth et al. ${ }^{1}$ and Lee et al. ${ }^{1,3}$ Major conclusions of the study are as follows:

1) Measurements yielded effective drop-burning rates of ca. $10 \mathrm{~mm} / \mathrm{s}$ for drop diameters of 300-1200 $\mu \mathrm{m}$ and pressures of 0.2-7 MPa. The effective drop-burning rate involved both reaction within the bulk liquid causing bubble formation and bursting, dominating the process at low pressures and conventional gasification from the drop surface, dominating the process at high pressures. Taken together, these effects cause burning rates to be relatively independent of pressure over the present test range.

2) Present measurements of drop-burning rates at pressures of 0.7-7 $\mathrm{MPa}$ are generally consistent with earlier strand burning-rate measurements of gelled propellants due to McBratney ${ }^{4,5}$ at pressures greater than $10 \mathrm{MPa}$.

3) Present measurements exhibited a much larger liquidcontaining region for combusting sprays at pressures of 3-9 $\mathrm{MPa}$ than the earlier measurements of Birk and Reeves ${ }^{19}$; even though test conditions and methods of data analysis were similar, e.g., $\bar{\alpha}_{f_{c}}=0.5$ at $x / d$ roughly 150 and 25 for the two sets of experiments. Reasons for these differences have not been firmly established, but different injector passage conditions, possibly leading to effects of cavitation, swirl, and finer atomization for the measurements of Ref. 19, have been advanced as a possible explanation.
4) Although earlier evaluation of predictions using the LHF and thin laminar flamelet approximations appeared promising based on the measurements of Birk and Reeves, ${ }^{19}$ current findings suggest that this approach substantially overestimates the rate of development of the flow, which is consistent with recent findings for other pressure-atomized spray processes. ${ }^{11-13}$ Separated-flow phenomena appear to be important for combusting HAN-based monopropellant sprays over much of their range of application.

\section{Acknowledgments}

This research was sponsored by the Army Research Office and the U.S. Army Armament Research, Development and Engineering Center, Picatinney Arsenal, NJ, under Contract DAAL03-86-K-0154.

\section{References}

${ }^{1}$ Faeth, G. M., Lee, T.-W., and Kounalakis, M. E., "Mixing and Thermodynamic Critical Phenomena of Combusting Monopropellant Sprays," Proceedings of the 24th JANNAF Combustion Meeting, Chemical Propulsion Information Agency, Applied Physics Laboratory, Laurel, MD, Oct. 1987.

${ }^{2}$ Kounalakis, M. E., and Faeth, G. M., "Combustion of HANBased Liquid Monopropellants Near the Thermodynamic Critical Point," Combustion and Flame, Vol. 74, No 2, Nov. 1988, pp. 179-192.

${ }^{3}$ Lee, T.-W., Gore, J. P., Faeth, G. M., and Birk, A., "Analysis of Combusting High-Pressure Monopropellant Sprays," Combustion Science and Technology, Vol. 57, No. 4, 1988, pp. 95-112.

${ }^{4}$ McBratney, W. F., "Windowed Chamber Investigation of the Burning Rate of Liquid Monopropellants for Guns," Ballistic Research Lab., Aberdeen Proving Ground, MD, Rept. ARBL-MR03018 , April 1980.

${ }^{5}$ McBratney, W. F., “Burning Rate Data LGP 1845," Ballistic Research Lab., Aberdeen Proving Ground, MD, Rept. ARBL-MR03128 , Aug. 1981 .

${ }^{6}$ Vosen, S. R., "The Burning Rate of HAN-Based Liquid Propellants," Proceedings of the Twenty-Second Symposium (International) on Combustion, The Combustion Institute, Pittsburgh, PA, 1988, pp. 1817-1825.

${ }^{7}$ Zhu, D. L., and Law, C. K., "Aerothermochemical Studies of Energetic Liquid Materials: 1. Combustion of HAN-Based Liquid Gun Propellants Under Atmospheric Pressure," Combustion and Flame, Vol. 70, Dec. 1987, pp. 333-342.

${ }^{8}$ Beyer, R. A., "Atmospheric Pressure Studies of Liquid Monopropellant Drops in Hot Flows," Ballistic Research Lab., Aberdeen Proving Ground, MD, BRL-TR-2768, Oct. 1986.

${ }^{9}$ Beyer, R. A., "'Single Droplet Studies in a Hot, High Pressure Environment," Ballistic Research Lab., Aberdeen Proving Ground, MD, BRL-TR-2900, March 1988.

${ }^{10}$ Beyer, R. A., and Teague, M. W., "Studies of Single Liquid Propellant Drops in Hot, High Pressure Environments," 22nd JANNAF Combustion Meeting, Chemical Propulsion Information Agency, Applied Physics Laboratory, Laurel, MD, CPIA Publ. 457, Vol. 2, Oct. 1986 , p. 429.

${ }^{11}$ Faeth, G. M., "Evaporation and Combustion in Sprays," Progress in Energy Combustion Science, Vol. 9, 1983, pp. 1-76.

${ }^{12}$ Faeth, G. M., "Mixing, Transport, and Combustion in Sprays," Progress in Energy Combustion Science, Vol. 13, 1987, pp. 293-345.

${ }^{13}$ Ruff, G. A., Sagar, A. D., and Faeth, G. M., "Structure and Mixing Properties of Pressure-Atomized Sprays,"' AIAA Journal, Vol. 27, July 1989, pp. 901-908.

${ }^{14}$ Bray, K. N. C., "Interaction Between Turbulence and Combustion,"' Proceedings of the Seventeenth Symposium (International) on Combustion, The Combustion Institute, Pittsburgh, PA, 1978, pp. 223-233.

${ }^{15}$ Bray, K. N. C., "Turbulent Flows with Premixed Reactants," Turbulent Reacting Flows, edited by P. A. Libby and F. A. Williams, Springer, Berlin, 1980, pp. 115-135.

${ }^{16}$ Bilger, R. W., "Turbulent Jet Diffusion Flames," Progress in Energy Combustion Science, Vol. 1, No. 2, 1976, pp. 87-109.

${ }^{17}$ Jeng, S. M., and Faeth, G. M., "Species Concentrations and Turbulence Properties in Buoyant Methane Diffusion Flames," Journal of Heat Transfer, Vol. 106, No. 4, Nov. 1984, pp. 721-727.

${ }^{18}$ Lockwood, F. C., and Naguib, A. S., "The Prediction of Fluc- 
tuations in the Properties of Free, Round Jet, Turbulent Diffusion Flames," Combustion and Flame, Vol. 24, No. 1, Feb. 1975, pp. 109-124.

${ }^{19}$ Birk, A., and Reeves, P., "Annular Liquid Propellant Jets--Injection, Atomization and Ignition," Ballistic Research Lab., Aberdeen Proving Ground, MD, BRL-TR-2780, March 1987.

${ }^{20}$ Gordon, S., and McBride, B. J., "Computer Program for Calculation of Complex Chemical Equilibrium Compositions, Rocket Performance, Incident and Reflected Shocks and Chapman-Jouguet Detonations," NASA Rept. SP-273, 1971.

\begin{abstract}
${ }^{21}$ Faeth, G. M., Gore, J. P., Chuech, S. G., and Jeng, S. M., "Radiation from Turbulent Diffusion Flames," Annual Review Numerical Fluid Mechanics and Heat Transfer, Vol. 2, 1988, pp. 1-38.

${ }^{22}$ Shearer, A. J., Tamura, H., and Faeth, G. M., "Evaluation of a Locally Homogeneous Flow Model of Spray Evaporation,' Journal of Energy, Vol. 3, Sept.-Oct. 1979, pp. 271-278.

${ }^{23} \mathrm{Mao}$, C. P., Wakamatsu, Y., and Faeth, G. M., "A Simplified Model of High Pressure Spray Combustion," Proceedings of the Eighteenth Symposium (International) on Combustion, The Combustion Institute, Pittsburgh, PA, 1980, pp. 337-347.
\end{abstract}

\section{ATTENTION JOURNAL AUTHORS: SEND US YOUR MANUSCRIPT DISK}

AIAA now has equipment that can convert virtually any disk $\left(31 / 2-, 51 \frac{1}{4-}\right.$, or 8 -inch) directly to type, thus avoiding rekeyboarding and subsequent introduction of errors. The mathematics will be typeset in the traditional manner, but with your cooperation we can convert text.

You can help us in the following way. If your manuscript was prepared with a word-processing program, please retain the disk until the review process has been completed and final revisions have been incorporated in your paper. Then send the Associate Editor all of the following:

- Your final version of double-spaced hard copy.

- Original artwork.

- A copy of the revised disk (with software identified).

Retain the original disk.

If your revised paper is accepted for publication, the Associate Editor will send the entire package just described to the AIAA Editorial Department for copy editing and typesetting.

Please note that your paper may be typeset in the traditional manner if problems arise during the conversion. A problem may be caused, for instance, by using a "program within a program"' (e.g., special mathematical enhancements to word-processing programs). That potential problem may be avoided if you specifically identify the enhancement and the word-processing program.

In any case you will, as always, receive galley proofs before publication. They will reflect all copy and style changes made by the Editorial Department.

We will send you an AIAA tie or scarf (your choice) as a "thank you" for cooperating in our disk conversion program. Just send us a note when you return your galley proofs to let us know which you prefer.

If you have any questions or need further information on disk conversion, please telephone Richard Gaskin, AIAA Production Manager, at (202) 646-7496. 